\title{
Uma Contribuição à Discussão Sobre a Avaliação de Desempenho das Instituições Federais de Ensino Superior - Uma Abordagem da Gestão Econômica*
}

\author{
Luís Paulo Guimarães dos Santos \\ Mestrando em Controladoria e Contabilidade pela FEA/USP \\ Professor do Departamento de Ciências Contábeis da Universidade Federal da Bahia
}

\section{RESUMO}

Partindo do pressuposto de que o resultado econômico é a melhor medida de eficácia para qualquer tipo de entidade, o presente trabalho procura abordar a problemática da avaliação das instituições federais de ensino sob a ótica do modelo da gestão econômica, destacando as vantagens conceituais e operacionais de se estabelecer um critério de avaliação por resultados econômicos.

A partir da análise feita por alguns estudiosos da avaliação de desempenho em instituições de ensino superior, são descritas algumas das principais deficiências dos modelos atuais de avaliação que são adotados pelo governo, principalmente pelo fato de não permitirem a identificação das reais contribuições geradas por estas instituições em termos de benefício sociais que possuem uma expressão econômica de valor.

Um modelo operacional de apuração do resultado econômico para esse tipo de entidade é apresentado, bem como um modelo operacional de informação, com destaque ao processo de orçamentação, evidenciando sua importância na geração de informações sobre os resultados previstos e realizados como forma de subsidiar o processo de gestão e a implementação de ações corretivas por parte dos gestores a fim de que possam otimizar os resultados das suas ações gerenciais, na busca do melhor resultado econômico para as instituições federais de ensino superior.

Palavras-chave: Avaliação de Desempenho; Gestão Econômica; Resultado Econômico; Avaliação Institucional
ABSTRACT

Starting from the presupposition that the economic result is the best efficiency measure for any kind of entity, this paper seeks to approach the problem about the evaluation of federal education institutions from the perspective of the economic management model, highlighting the conceptual and operational advantages of establishing an evaluation criterion in accordance with economic results.

On the basis of the performance evaluation analysis realized by some scholars in higher education institutions, we describe some of the main deficiencies of the current evaluation models adopted by the government, mainly because they do not allow for the identification of the real contributions generated by these institutions in terms of social benefits that can be expressed as an economic value.

We present an operational model for determining the economic result for this kind of entity, as well as an operational information model, highlighting the budgetary process and demonstrating its importance when generating information on the previewed and actual results, as a way of helping the management process, as well as when implementing corrective actions by managers for them to be able to optimize the results of their managerial actions, in search of the best economic result for the federal higher education institutions.

Keywords: Performance Evaluation, Economic Management, Economic Result, Institutional Evaluation

* Artigo publicado nos Anais do XVI Congresso Brasileiro de Contabilidade, realizado de15 a 20 de outubro de 2000 - Goiânia/GO. 


\section{INTRODUÇÃO}

Existe um consenso sobre a necessidade e a urgência de ser implantado um processo de avaliação de desempenho no âmbito das Universidades Federais de Ensino Superior - IFES. É consenso também a importância do processo em curso como elemento de motivação e sensibilização e como levantamento exploratório para o estabelecimento de práticas e dos referenciais teóricos e metodológicos que deverão dar forma e conteúdo a uma proposta global de avaliação. Para isto é necessário que a universidade implemente um programa de capacitação que assegure o manejo e operação do que é modernamente concebido como avaliação.

No Brasil cresce a consciência sobre a necessidade de se desenvolverem sistemas de avaliação do ensino superior, principalmente por parte do Governo Federal, que se ressente da falta de critérios adequados para a distribuição de recursos para as IFES; pelas IFES, que necessitam conhecer melhor a si próprias, e comparar com informações adequadas e consistentes as críticas que freqüentemente recebem de serem ineficazes na aplicação de recursos públicos; e pela própria sociedade, que não dispõe de formas concretas de avaliar a contribuição social que as IFES dão pelo consumo de recursos públicos bancados por todos.

A necessidade crescente de formas e processos de avaliação das IFES revela o imperativo de se buscar uma melhor fundamentação conceitual-teórica para proceder à análise das visões que se tem acerca das propostas vigentes e para sustentar atuais e futuros posicionamentos que se possam assumir diante das mesmas.

Contextualmente, portanto, uma questão se faz premente: Como avaliar, com justiça, uma organização multifacetada que possui características bastante diferenciadas das demais organizações públicas e que gera benefícios sociais bastante difíceis de serem mensurados em função dos diferentes papéis que assume na sociedade?

A resposta para esta questão talvez esteja na avaliação dos próprios objetivos sociais a que estas instituições se destinam, a partir de uma abordagem voltada para a mensuração do resultado econômico produzido pelas mesmas. O pressuposto básico é o de que a maximização dos objetivos sociais de uma IFES depende da sua eficácia na utilização dos recursos econômicos postos a sua disposição; e que o valor econômico dos benefícios sociais transferidos por elas à sociedade é o mais justo parâmetro de avaliação de desempenho, pois os resultados econômicos originados das ações postas em prática estão consoantes com os benefícios sociais desejados.

\section{AVALIAÇÃO DE DESEMPENHO, UM BREVE ENTENDIMENTO}

Avaliar significa diferenciar. Por isso, sistemas de avaliação só surgem e se impõem quando os interesses a favor da diferenciação superam os interesses dos que preferem a igualdade indiferenciada (Schwartzman, 1986:01).

Conforme Pereira (1993:127), a avaliação de desempenho pode ter vários significados em função do sentido atribuído ao termo "avaliação" e do contexto relativo ao "desempenho", objeto dessa avaliação. Para o autor, avaliar desempenho significa julgar ou atribuir um conceito diante de expectativas pré-estabelecidas.

Para Pereira (1993:127), no contexto empresarial o desempenho assume dimensões variadas quando relaciona às suas áreas de responsabilidade, às suas funções organizacionais, aos seus aspectos operacionais econômicos e financeiros, às atividades planejadas e realizadas, ou a empresa como um todo. Dessa forma, o processo de gestão da empresa, consubstanciado nas fases de planejamento, execução e controle, requer avaliações desses desempenhos, como um requisito para o exercício do controle, que interage com as demais fases do processo. Neste contexto, avaliar desempenho passa a ser um meio para se tomarem decisões adequadas, constituindose num processo complexo que agrega as características informativas essenciais para se avaliar adequadamente um desempenho e as condições essenciais para se integrar ao processo de gestão, no seu ciclo planejamento-execução-controle.

Por outro lado, "o termo 'avaliação' refere-se ao ato ou efeito de se atribuir valor, sendo que 'valor' pode ser entendido num sentido qualitativo (mérito, importância) ou num sentido quantitativo (mensuração)". (Pereira, 1993:128).

Gibson et al. (apud Pereira, 1993:130) consideram que a questão da eficácia está relacionada à do desempenho. Os gestores estão voltados para o desem- 
penho, pois os processos de planejamento, execução e controle materializam o conceito de desempenho. De acordo com os autores, "o planejamento estabelece as expectativas, o organizador implanta essas expectativas e o controller avalia o desempenho das expectativas estabelecidas e implantadas". Em função do descrito, a eficácia pode ser considerada como um julgamento dos administradores no exercício da função de controle.

Nas afirmações de Gibson et al., Pereira (1993:13031) considera que constam os elementos necessários à caracterização da avaliação de desempenho no contexto empresarial:

- o conceito de desempenho, de expectativas préestabelecidas;

- a estreita relação com o processo de gestão e o aspecto qualitativo (eficácia) do desempenho, como uma das principais preocupações ao se avaliar um desempenho.

Para Peleias (1992:114) "a avaliação de desempenho pressupõe um referencial ou um parâmetro para comparação, contra o qual o desempenho será confrontado - este parâmetro poderá ser expresso tanto em termos físicos ou financeiros, ou ambos". Complementando esta noção de avaliação de desempenho, o autor destaca ainda que o estabelecimento de um intervalo de tempo para que a avaliação de desempenho se realize é necessário, pois permitirá que a avaliação seja operacionalizada sem a necessidade de paralisação de atividades para a sua realização.

A avaliação de desempenho pode ser focada sob uma área de responsabilidade ou sob um gestor especificamente. Peleias (1992:10-11) nos revela que na literatura especializada os diversos autores destacam aspectos distintos sob a avaliação de desempenho, citando que:

- Bierman e Drebin demonstram preocupação com o conteúdo dos relatórios e a delegação de autoridade, e consideram a que a avaliação de performance pode ser encarada como um caso especial de controle de custos.

- Mcnair e Mosconi focalizam sua atenção com a verificação da eficácia, eficiência e relação da empresa com seu ambiente externo e destacam o papel da avaliação de desempenho como forma da empresa alcançar excelência na produção.
- Newman focaliza a avaliação de desempenho como instrumento para a tomada de ações corretivas para assegurar que os resultados obtidos estejam de acordo com os planos estabelecidos através do estabelecimento de padrões para a avaliação.

- Catelli focaliza a questão da avaliação de desempenho a partir da evidenciação da sua estreita relação com o planejamento e controle, destacando que em função das metas estabelecidas e das políticas da empresa, a administração desprenderá seus esforços para que as mesmas sejam alcançadas com o desempenho esperado.

- Fernadez focaliza a importância da qualidade da informação e a importância dos padrões para uma adequada mensuração do desempenho.

- Glautier \& Underdown focalizam a necessidade da identificação das áreas de responsabilidade e o estabelecimento de padrões de desempenho para uma adequada avaliação de desempenho.

Diante das análises desses autores, Peleias (1992:12) conclui que a avaliação de desempenho requer medidas de desempenho tanto qualitativas quanto quantitativas e que a ênfase em objetivos específicos pode significar que outros objetivos não sejam alcançados, pois os "objetivos da avaliação de desempenho requerem uma visão balanceada do desempenho relativa às várias áreas de responsabilidade".

Por seu turno, Guerreiro (1989:22) distingue a avaliação de desempenho da avaliação de resultado. Segundo o autor, a avaliação de resultado trata da análise da rentabilidade dos produtos e serviços e a avaliação de desempenho trata da análise do desempenho das áreas de responsabilidade da empresa do ponto do vista da sua contribuição para a formação do resultado econômico global. Esta diferenciação é importante para poder determinar o papel central do sistema de informações contábeis, que deve dirigir-se a evidenciar quais áreas e atividades contribuem mais ou menos para a formação do resultado econômico.

A partir das considerações abordadas sobre avaliação de desempenho e das conclusões de Pereira (1993:132), pode-se assumir que o principal fator no desenvolvimento de metodologias de avaliação de desempenho é atentar para a questão de essas metodologias "não permitirem apenas conclusões so- 
bre a qualidade de um desempenho, mas principalmente impulsioná-lo ao atendimento de qualidades (eficácia, eficiência) julgadas ideais e desejáveis".

\section{A AUTONOMIA UNIVERSITÁRIA: UMA SAÍDA PARA GESTÃO FLEXÍVEL DAS IFES E IMPLEMENTAÇÃO DE CRITÉRIOS ADEQUADOS PARA UMA AVALIAÇÃO DE DESEMPENHO JUSTA}

O debate sobre a autonomia foi reintroduzido pelo MEC com o lançamento do documento Autonomia Universitária, que contém as diretrizes para a formulação de um projeto de lei que regulamente o artigo 207 da Constituição. De acordo com este artigo, "As universidades gozam de autonomia didático-científica, administrativa e de gestão financeira e patrimonial, e obedecerão ao princípio de indissociabilidade entre ensino, pesquisa e extensão". A controvérsia atual se desenvolve em torno da auto-aplicabilidade versus necessidade de regulamentação do referido artigo.

A efetiva implantação da autonomia das universidades federais constitui-se em meta prioritária do Ministério da Educação para a educação superior. Pela autonomia busca-se um modelo de gestão que corresponda ao atual estágio de desenvolvimento e expansão da universidade federal, reforçando seu caráter público, sua capacidade de planejamento institucional e o aproveitamento mais racional dos investimentos públicos que nela são feitos. A partir daí será possível, de modo sistemático, associar recursos à eficiência na gestão e no desempenho de cada instituição.

A lógica da implementação de um programa nos moldes do que preconiza o Projeto Autonomia Universitária consubstancia-se no fato de que as IFES constituem organizações complexas e sujeitas a fortes pressões externas e internas, com níveis de decisão e responsabilidade diluídos e mal definidos, dirigidas por profissionais se originam de áreas de ensino e pesquisa que nada têm a ver com gestão ou administração, com mandatos, em geral, curtos para os objetivos a que se elegem e não renováveis.

Por sua configuração sócio-política, as IFES tendem a ser paternalistas com a própria comunidade, avessas a qualquer forma de burocracia e planejamento central e mais preocupadas com seus problemas internos do que com seu papel dentro da sociedade, como formadora das bases fundamentais para o seu desenvolvimento sustentado através da formação de profissionais preparados para atender as demandas e formação de massa crítica que definirá a nossa posição no mundo globalizado e radicalmente transformado pelas mais recentes revoluções políticas, econômicas e tecnológicas.

Atualmente, as IFES vêm sofrendo pressões para atender a mais estudantes, sem a devida contrapartida orçamentária, para atender às demandas de maior envolvimento com o desenvolvimento sócio-econômico regional e nacional, para suplementar o estado em programas de atendimento social e para serem eficientes na gestão de seus recursos, sejam eles públicos ou privados, o que exige um processo de transformação e modernização internos. É também claro que esse processo deve preservar a flexibilidade interna, o poder de adaptação da universidade e a liberdade de criação e de crítica.

Neste cenário, o governo federal vem desenvolvendo políticas gerenciais e legais para favorecer o desenvolvimento de ações administrativas e corporativas no âmbito das IFES que garantam o cumprimento das metas impostas pelo poder central. Exemplo dessas ações é o Projeto de Autonomia Universitária em discussão atualmente, sendo sua implementação nas instituições de ensino superior uma das principais metas do Ministério da Educação e Cultura.

Nas palavras do próprio ministério, a autonomia universitária objetiva criar um modelo de gestão que corresponda ao atual estágio de desenvolvimento e expansão da universidade federal, reforçando seu caráter público, sua capacidade de planejamento institucional e o aproveitamento mais racional dos investimentos públicos que nela são feitos. A partir daí será possível, de modo sistemático, associar recursos à eficácia na gestão e no desempenho de cada instituição.

A Autonomia tentará criar um cenário diferenciado para a atuação das IFES, livres das amarras legais aplicáveis a todas instituições públicas federais, principalmente em matéria de gestão de pessoal e elaboração e execução orçamentária e financeira, que são incompatíveis com as características organizacionais de uma instituição de ensino superior, criando formas viáveis do pleno exercício do que se preconiza no artigo 207 da Constituição Federal. 
O projeto de lei que trata da Autonomia Universitária focaliza as seguintes diretrizes principais:

a) garantia do caráter público e do financiamento estável, com alocação transparente de recursos baseados na indissociabilidade do ensino, da pesquisa e da extensão; b) avaliação institucional; e c) auto-organização no que concerne à administração dos recursos humanos e execução orçamentária.

A garantia de um orçamento global, fixado a partir de critérios objetivos de desempenho institucional, representa componente indispensável a esse processo. O governo federal, por sua vez, incumbir-se-á de garantir a manutenção e a estabilidade dos investimentos e gastos anuais com as universidades federais. O Ministério da Educação manterá suas ações de apoio e de fomento a programas, como os de qualificação à modernização do ensino de graduação, de expansão da base institucional de pesquisa e pósgraduação por região, e da expansão de oferta de vagas. Formando-se, dessa forma, o binômio desempenho institucional-garantia estatal, como base para a delineação do instrumento de desenvolvimento acadêmico e administrativo das IFES.

\section{UMA ANÁLISE DA IDÉIA ATUAL DE AVALIAÇÃO NAS INSTITUIÇÕES DE ENSINO}

Por sua vez, Schwartzman (1989) destaca que a prática da avaliação institucional pode se desenvolver em função de dois enfoques básicos: um centrado nas importâncias contáveis (custo por aluno, número de alunos matriculados etc.) e de fiscalização (o Estado avaliador), e outro centrado nos processos organizacionais do processo de ensino. O primeiro faz referência a aspectos de eficiência e fatores econômicos (otimização dos recursos disponíveis) e se orienta em direção ao controle por parte das instituições governamentais.

Schwartzman (1989) acredita que um processo avaliativo deve ser entendido como uma atividade contínua e aberta mediante a qual todos os setores envolvidos com o ensino superior aprendem a pensar em termos de objetivos, desempenho e qualidade, e que tem como resultado a melhoria progressiva do desempenho do sistema de ensino superior como um todo e de cada instituição em particular. De um processo dessa natureza, não se deve esperar que desapareçam as dúvidas, as discordâncias e as contradições que sempre existem em qualquer sistema educativo vivo e dinâmico; mas ele será, sem dúvida, um sistema mais sadio e mais adequado a seus fins.

A análise das intenções, ou objetivos, é um aspecto da maior importância em qualquer pesquisa avaliativa, mas tem seu lugar próprio e determinado. É necessário saber, em primeiro lugar, quais são os objetivos explícitos buscados por uma instituição de ensino em seu trabalho. Este objetivo explícito está freqüentemente expresso em documentos escritos pertinentes a um curso ou a uma profissão, e podem servir de parâmetros para a avaliação dos resultados. Em outras palavras, a missão da instituição e a eficácia no seu cumprimento são um parâmetro objetivo de avaliação.

Como destaca Schwartzman (1989), efeitos positivos aferidos pelo processo avaliativo se explicam totalmente por variáveis não educacionais, como por exemplo a origem sócio-econômica dos estudantes ou a localização geográfica da instituição de ensino. Nessa situação, os resultados da avaliação podem ser totalmente ilegítimos. A segunda ocorre quando existe um efeito educacional discernível, ainda que este efeito seja totalmente explicável por variáveis externas. Uma determinada instituição com muitos recursos, por exemplo, será possivelmente melhor do que outra sem recursos; trata-se de uma diferença genuína do ponto de vista educacional, por causas externas aparentemente óbvias. A terceira situação, mais rara, ocorre quando as diferenças de resultado derivam exclusivamente de características internas, como por exemplo a adoção de determinadas metodologias de ensino ou determinadas políticas de recrutamento de professores.

A pesquisa avaliativa revela também, com freqüência, que existe um alto grau de associação entre diversas dimensões da avaliação, o que significa, muitas vezes, a existência de uma relação causal entre elas (Schwartzman, 1989). Se esta relação for suficientemente comprovada e estável, isto significará que o conhecimento adquirido na escola de fato determina o resultado no mundo do trabalho, uma hipótese que nem sempre se verifica no mundo real. A existência de uma relação deste tipo poderia também tornar dispensável o estudo do desempenho profissional futuro, 
já que seria suficiente saber do conhecimento obtido pelo aluno nas instituições de ensino.

Na prática, estas relações causais entre diferentes dimensões avaliativas são menos estáveis e mais complexas do que se supõe, o que torna necessário avaliar resultados de forma independente e simultânea em vários níveis. A análise de causas, de relações ilegítimas e das interrelações entre as diferentes dimensões de desempenho requerem o trabalho de especialistas e permitem um conhecimento cada vez mais aprofundado da realidade educacional, assim como o desenvolvimento de instrumentos avaliativos cada vez mais aperfeiçoados. É importante não perder de vista, no entanto, que existe uma diferença profunda entre resultados e sua explicação, e que a pesquisa avaliativa se orienta, acima de tudo, para a determinação destes resultados.

Como esclarece Schwartzman (1989), a existência de um consenso nacional sobre a necessidade de avaliação não deve significar que todos estejam de acordo quanto à maneira pela qual esta avaliação deva ser feita, e menos ainda sobre como seus resultados podem vir a ser eventualmente utilizados. Isto decorre da falta que se sente de uma experiência consolidada sobre o assunto e a inexistência de metodologias de avaliação que estejam livres de questionamentos e discussões.

Schwartzman (1989) considera utópico imaginar que fosse possível chegar a uma metodologia de avaliação tão objetiva e perfeita que pudesse, por si mesma, eliminar as ambigüidades e contradições que são inerentes a qualquer empreendimento humano. $\mathrm{Na}$ opinião do autor, avaliações, por melhores que sejam, refletirão sempre valores de pessoas, e sempre existirão outras que pensarão de forma distinta.

Contudo, não obstante a questão de que a perfeição deve ser uma meta perseguida por todos, todo $e$ qualquer modelo de avaliação de desempenho organizacional deve levar em consideração a missão da entidade, e sua eficiência na consecução desta é que deve ser o principal parâmetro avaliativo.

Desordi (1999) alerta para as "ciladas" das atuais proposições avaliativas centradas no produto e que subestimam seu processo de sustentação. Para a autora, a lógica avaliativa atual já estava sendo superada a partir das críticas rigorosas e desconcertantes feitas pelos especialistas da área, evidenciando seus limites e falta de funcionalidade. Os critérios atuais de avaliação "guarda nítida dependência dos critérios quantitativos pensados por técnicos, à luz dos interesses que representam e que não são facilmente identificados".

Para Desordi (1999), o Exame Nacional de Cursos (ENC), bem como o parecer avaliativo emitido pelas Comissões de Especialistas entre outros, são formas de avaliação que valorizam sobremaneira a avaliação externa, a que se atribui pretensa neutralidade dandoIhe aparência de credibilidade incontestável. A autora considera que:

"... todo discurso sobre avaliação traz em seu interior fortes componentes ideológicos que permitem antever efetivamente o esquema axiológico que o rege. Não é apenas o que se fala, mas a forma como se fala e o quanto se fala que subsidiam a comunidade acadêmica e o público em geral para compreender o que vale em avaliação. O espaço e o tempo destinados para fazer circular as propostas inovadoras crescem na razão direta da importância das mesmas para a agenda educativa nacional".

Parafraseando Desordi (1999), a meta obsessiva de alcançar um padrão de qualidade abstratamente definido, desarticulado do critério da relevância e eficácia social, parece ser uma forte tendência, conseqüência das formas atuais de avaliação que também afetam as IFES e seus dirigentes.

A contribuição dada pelas IFES à sociedade não é levada em consideração nos modelos avaliativos atuais. Acredita-se que o grande interesse social não deva residir sobre o conceito que os estudantes do curso $X$ da instituição $Y$ obteve em uma avaliação equivocada, no que tange à sua forma e a seus objetivos, nem em saber o custo per capta do estudante universitário mensurado a partir de bases inconsistentes. O relevante é saber se a instituição está sendo eficaz no cumprimento de seus objetivos sociais.

As IFES ofertam serviços vitais e estratégicos para a sociedade através de suas atividades (ensino, pesquisa e extensão) "sem que estes benefícios sejam devidamente mensurados de forma a facilitar o processo de comunicação entre o agente benfeitor e o agente receptor, para justificar tais investimentos" (Vasconcelos, 1999:8). Isso faz com que se desconheçam os resultados econômicos que se materiali- 
zam através dos benefícios sociais específicos dos investimentos feitos pelo governo nessas instituições.

\section{O RESULTADO ECONÔMICO COMO PARÂMETRO AVALIATIVO DAS IFES}

As IFES, como qualquer outro tipo de organização, desenvolvem atividades que consomem fatores de produção, que por sua vez possuem valores econômicos correspondentes. Os serviços gerados pelas atividades são perfeitamente identificáveis sem que tenham um critério de avaliação associado. Este fato é significativamente relevante no momento de se avaliarem os gestores pela administração desses recursos e os resultados gerados como contrapartida. Nesse sentido, Vasconcelos (1999:19) revela: "A abordagem conceitual existente para tratamento dessas questões é inadequada ou insuficientemente discutida, impossibilitando a definição de uma gestão otimizadora dos recursos orçamentários recebidos, pela ausência de um modelo de avaliação baseado em resultados econômicos".

Outro aspecto destacado pelo autor diz respeito ao fato de que, pela ausência de parâmetros econômicos, os modelos atuais das prestações de contas feitas pelas IFES não evidenciam com verdade a real transferência para a sociedade dos benefícios que são gerados através de suas atividades; focalizadas apenas as ações geradas em termos de quantidade de recursos consumidos, impossibilitam uma adequada avaliação por parte dos mantenedores (sociedade e governo) da contribuição efetiva oferecida por essas instituições.

De acordo com Pereira (1999:54), "Qualquer atividade empresarial, em essência, é uma atividade econômica. O caráter econômico de uma atividade decorre do consumo de recursos que, por serem escassos, possuem valor econômico, e da geração de produtos/serviços, que também o possuem, por causa da utilidade ou satisfação que proporcionam aos seus clientes". As IFES se inserem neste ambiente, pois os produtos de suas atividades de ensino, pesquisa e extensão são um bem econômico tão valioso quanto qualquer outro que se negocie no mercado.

O resultado econômico positivo deve ser a meta objetivada pela IFES, pois este é responsável pela garantia da sua continuidade operacional. "A sua via- bilidade econômica associam-se decisões de investimentos em suas próprias atividades ou em outras..." (Pereira 1999:55).

Antes de proceder ao desenvolvimento das argumentações sobre a avaliação de desempenho baseada nos resultados econômicos gerados, necessário se faz definir o que representa este resultado e delinear as bases fundamentais de uma gestão centrada no resultado econômico.

O resultado econômico pode ser entendido como aquele que reflete a variação do patrimônio da empresa em um determinado período e que tenha sido corretamente mesurado sob a luz de conceitos econômicos. É considerado por Catelli et al. (1997) como a melhor medida de eficácia da empresa.

A destaque para a correta mensuração do resultado é ponto central para o desenvolvimento de um modelo de gestão baseada em resultados. A premissa de um modelo com este foco é de que "o resultado global da empresa é formado pelos resultados analíticos das diversas transações que correspondem à materialização das ações dos gestores (...) o nível de qualidade ou excelência da ação do gestor é fator decisivo para o grau de otimização do resultado" (Catelli et al. 1997:06). Neste contexto, os gestores devem ser avaliados exclusivamente pelos resultados gerados a partir de suas decisões no limite de suas responsabilidades, que devem estar claramente definidas pelo modelo de gestão da organização.

No caso das IFES, o modelo e gestão, que compreende o conjunto de normas, princípios e conceitos que têm por finalidade orientar seu processo administrativo para que possa cumprir sua missão, deve ser delineado a partir da implementação do que está prescrito no projeto de Autonomia Universitária. Os gestores dessas instituições devem estar livres das amarras burocráticas e legais que tornam o serviço público brasileiro ineficiente e inábil à implementação de ações gerenciais que visem a otimizar o resultado econômico dos serviços gerados, traduzidos pelos benefícios sociais disponibilizados à comunidade.

Para a correta mensuração dos resultados econômicos gerados, é necessário fazer uso de um conjunto de conceitos que permitam tal ação. A proposição básica nesse processo é de que o valor do patrimônio líquido tem de expressar o real valor da empresa e não o quanto custa ou custou. Como já havíamos descrito, a variação entre duas datas neste 
valor é o que se denomina resultado econômico. Os ativos e passivos da empresa devem ser mensurados individualmente pelos seus valores econômicos.

Segundo Guerreiro (1989:204), para uma correta mensuração do resultado econômico de uma entidade, faz-se necessária a observação de algumas considerações principais que devem ser levadas em conta, das quais se destacam:

1. o valor de um ativo é único e deve expressar o quanto vale para a empresa, em determinado momento;

2. o valor de um ativo não deve ser influenciado pelas condições de seu pagamento;

3. custos históricos não expressam o valor do ativo para a empresa;

4. a mensuração de ativos considera a continuidade do empreendimento;

5. a depreciação dos ativos corresponde à perda de seu potencial de geração de benefícios;

6. o valor de um ativo pode variar de uma empresa para outra;

7. devem ser considerados ganhos e perdas com valorização e desvalorização, respectivamente, de ativos, mesmo não realizados;

8. a receita dos produtos e serviços gerados deve ser reconhecida não somente na venda, mas também pela produção;

9. correção monetária de valores.
O resultado econômico das entidades forma-se a partir de suas atividades que se caracterizam pelo processamento de recursos escassos e possuidores, portanto, de valores econômicos na geração de bens e/ou serviços. Nesse processamento, o consumo de recursos é expresso através de custos, enquanto que os bens e/ou serviços produzidos expressam as receitas. Tanto os custos quanto as receitas recebem valores representados por expressões monetárias definidas no modelo de mensuração da empresa.

O resultado das atividades da empresa é apurado a partir de três dimensões fundamentais: operacional (resultado operacional); financeira (resultado financeiro); econômica (resultado econômico). A primeira dimensão diz respeito à tradução em valores econômicos da produção física de bens/serviços, a segunda diz respeito às operações de compras, vendas, recebimentos e pagamentos que envolvem prazos, e a terceira representa a soma dos anteriores.

\section{APURAÇÃO DO RESULTADO ECONÔMICO NAS IFES}

O resultado econômico das IFES é apurado da mesma forma com que se apuram os resultados de qualquer entidade que possua ou não fins lucrativos. A equação básica para tal processo pode ser assim expressa:

Tabela 01: Equação do Resultado Econômico

\begin{tabular}{|l}
$1-(+)$ Receita Operacional \\
$2-(-)$ Custos Variáveis \\
$3-(=)$ Margem de Contribuição Operacional (1-2) \\
$4-$ Custos/Despesas Fixas \\
$5-(=)$ Resultado Econômico da Atividade/Área (3-4)
\end{tabular}

A apuração do resultado econômico nas IFES deve estar sustentada em alguns conceitos de mensuração, permitindo que o mesmo seja apurado corretamente. Dentre esses conceitos, destacam-se os seguintes: Preço de Transferência; Valor Presente; Moeda Constante; Custo de Oportunidade e Custo Corrente de Reposição.
A receita operacional deve corresponder à melhor alternativa (menor preço de mercado à vista) que os mantenedores estão deixando de pagar pela decisão de manter a IFES. Representa, portanto, o seu custo de oportunidade.

Os custos variáveis correspondem aos valores dos insumos utilizados pelas IFES na produção de bens/ 
serviços e que possam ser diretamente identificados aos mesmos, mensurados pelos seus valores de mercado à vista, representado o seu custo corrente de reposição.

Os custos/despesas fixas se referem ao consumo de recursos identificados no período e que, portanto, não pertencem aos produtos/serviços produzidos pelas IFES.

\section{A AVALIAÇÃO DE DESEMPENHO NO CONTEXTO DA GESTÃO ECONÔMICA}

No contexto da Gestão Econômica a Avaliação de Desempenho refere-se à avaliação dos resultados gerados pelas atividades sob responsabilidade dos gestores. "A associação desses resultados a responsabilidades de seus respectivos gestores permite identificar as suas contribuições e as de suas áreas aos resultados globais" (Pereira, 1999:215).

A avaliação dos gestores deve ser feita com base na sua autoridade, definida no modelo de gestão da empresa. Só devem ser avaliadas aquelas decisões que lhe competem, pelas suas responsabilidades. As decisões tomadas pelos gestores não consomem recursos apenas, geram receitas, e o resultado determinado a partir do confronto dessas receitas com os custos é que deve ser o parâmetro de avaliação de desempenho.

A premissa fundamental do modelo de gestão preconizado é de que os gestores, ao realizarem a gestão econômica das atividades que estão sob sua responsabilidade, produzem um resultado econômico, que deve ser a sua medida de eficácia. Pereira (1999:215), nesse sentido, considera:

"As informações para avaliação de desempenhos, na gestão econômica, referem-se especificamente às atividades realizadas nas áreas sob a responsabilidade dos gestores, constituindo, portanto, fortes indicadores para a avaliação de desempenho dos gestores. Demonstram como vêm conduzindo tais atividades, no exercício de suas funções e diante da autoridade que Ihes foram delegadas para gerir recursos, visando ao atendimento dos objetivos da empresa".
No âmbito das IFES a avaliação de desempenho é feita com base em dois critérios principais: a eficiência no consumo de recursos (base de custo); e gestão dos processos organizacionais da atividade de ensino. Ambos fundamentam-se em critérios equivocados de avaliação, pois:

1. As atividades desenvolvidas pelas IFES não apenas consomem recursos; como qualquer outra atividade econômica, geram receitas e conseqüentemente resultado. Esse resultado está em consonância com os objetivos sociais dessas entidades na medida em que possam ser traduzidos em benefícios para a sociedade. Além do que esse critério gera informações distorcidas sobre o desempenho da instituição, dependendo das políticas estratégicas definidas pelos órgãos de planejamento do governo. Por exemplo: é muito comum o governo fazer investimentos específicos em determinadas regiões do país ou área de conhecimento destinando verbas adicionais para promover o desenvolvimento regional e científico em determinadas instituições de ensino, aumentado significativamente os custos totais da mesma, sem um aumento proporcional no número de vagas ofertadas nesta instituição, porém com significativo impacto social.

2. Estabelecer parâmetros avaliativos a partir de critério subjetivos como, por exemplo, o desempenho dos alunos das instituições de ensino em provas específicas de conhecimento não leva em consideração que tal desempenho pode estar refletindo vários aspectos abstratos da formação do indivíduo, tais como fatores socioeconômicos, fatores psicossociais, influências de práticas pedagógicas diferenciadas, dentre outras que podem ser facilmente identificadas nos diversos compêndios dos autores de educação e psicologia que versam sobre o tema.

Como já descrito anteriormente, o resultado mensurado corretamente é a mais consistente medida de eficácia da organização, pois, segundo Pereira (1999:72), "expressa todos os esforços e benefícios obtidos pela empresa no sentido de cumprir sua missão, quantificando o impacto econômico de todos os eventos que alteram seu patrimônio, sejam esses eventos decorrentes das decisões internas ou de fa- 
tores tempo-conjunturais".

Pereira (1999:72-75) destaca ainda as seguintes vantagens do resultado econômico como parâmetro avaliativo:

- Representa o incremento da riqueza da entidade, de seu patrimônio e de seu valor;

- reflete as condições de sobrevivência, desenvolvimento, adaptabilidade, produção, eficiência e satisfação;

- possui caráter preditivo da eficácia;

- evidencia a responsabilidade da empresa no uso de recursos escassos de forma eficiente e eficaz;

- expressa a contribuição das atividades e áreas que desenvolvem à eficácia empresarial;

- permite constituir modelos flexíveis de análise e decisões econômicas.

Na gestão econômica, a avaliação de desempenho requer bases informativas relativas ao desempenho realizado e planejado, a fim de que se possa estabelecer comparabilidade dessas bases, devendo voltar-se, no que se refere ao desempenho realizado, para o futuro, ao que se deseja atingir a partir das condições previstas.

Para o atendimento das condições prescritas no parágrafo anterior, os orçamentos e os padrões de desempenho apresentam-se como bases adequadas de comparação para avaliação de desempenho.

\section{Alguns Princípios Para Avaliação de Desempenho na Gestão Econômica}

Conforme nos ensina Pereira (1999:250-3), na gestão econômica são utilizados alguns critérios genéricos que orientam a avaliação de desempenho, que são agrupados conforme se refiram aos modelos de decisão, mensuração e informação, dentre os quais destacamos:

Relativos ao Modelo de Decisão - este modelo diz respeito à forma como as decisões são tomadas. O pressuposto da gestão econômica é de que a avaliação de desempenho está intimamente relacionada com o processo decisório dos gestores, integrando-se às fases de planejamento, execução e controle. Os seguintes aspectos referentes à avaliação de desempenho são parâmetros de orienta- ção no modelo:

- As atividades representam o foco da atenção na tomada de decisão;

- os conceitos econômicos devem ser a base das decisões do gestores;

- decisões econômicas devem buscar otimização dos resultados das atividades;

- devem ser considerados todos os efeitos de uma única decisão sobre as atividades em suas dimensões operacional, financeira e econômica;

- as decisões devem objetivar incrementar a qualidade das atividades, em seus níveis de eficiência e eficácia relativas ao desempenho planejado e realizado;

- o modelo de decisão econômica deve ser único para todos os gestores da empresa;

- os desempenhos devem ser avaliados mediante a aplicação do conceito de custo de oportunidade, toda vez que haja possibilidade de usos alternativos de recursos.

Relativos ao Modelo de Mensuração - este modelo representa a forma como são medidos ou quantificados os atributos de algum objeto. Na gestão econômica, a avaliação de desempenho, que é mensurada em termos físicos e monetários, se baseia nos resultados gerados pelas atividades associadas às áreas de responsabilidade dos gestores e considera os seguintes aspectos fundamentais:

- integração aos modelos de decisão e informação;

- mensuração dos resultados baseada nas atividades operacionais;

- precisão das medidas, de forma a refletir o valor econômico dos recursos;

- devem ser mensurados os efeitos econômicos de caráter operacional e financeiros das decisões;

- a transferência de produtos e serviços entre as atividades deve basear-se em preços-padrões validados pelo mercado, sendo o custo de oportunidade o mais adequado parâmetro;

- os custos fixos não devem ser rateados entre produtos e/ou serviços, atividades ou áreas de responsabilidade;

- a mensuração do desempenho deve espelhar a contribuição das atividades para a formação do resultado econômico global da entidade;

- todos os eventos semelhantes devem ser 
mensurados sob uma mesma base conceitual;

- os conceitos de mensuração devem ser explícitos e compreendidos pelos usuários da informação.

Relativos ao Modelo de Informação - por este modelo entende-se a forma como as informações devem ser entendidas, orientado para a articulação do sistema de informação da empresa. Neste contexto, é essencial que os gestores da organização tenham uma preocupação com a informação focalizada em sua utilidade, conteúdo, disponibilidade, oportunidade e custo-benefício, devendo propiciar um perfeito conhecimento da realidade das atividades, subsidiando uma adequada avaliação de desempenho.

Para que a informação cumpra seu real papel no processo de gestão da empresa, necessário se faz que esta incorpore os seguintes aspectos tangentes ao seu processo de identificação, acumulação e identificação:

- deve estar integrada aos modelos de decisão e mensuração;

- a empresa deve ser segmentada em áreas de responsabilidade, permitindo que se identifiquem as receitas e custos e posterior apuração de resultado;

- as informações sobre custos e receitas devem ser acumuladas segundo os conceitos de centro de custos, de resultado e de investimentos, dependendo das necessidades de controles definidas pelos gestores. Para uma adequada avaliação de desempenho, as áreas de responsabilidade devem corresponder a centros de resultados e investimentos;

- a geração de informações sobre desempenhos planejado e realizado deve utilizar a mesma base conceitual, garantindo um grau de uniformidade ideal;

- as informações sobre desempenho devem des- tacar a contribuição das atividades para formação do resultado econômico global da entidade, identificando os efeitos econômicos dos aspectos operacional e financeiro das mesmas;

- o modelo de informação deve ser configurado de forma a evidenciar as causas das variações entre os desempenhos planejado e realizado, de uma forma detalhada e a partir dos conceitos de orçamento flexível, padrões e equação de resultado;

- as informações sobre desempenho devem evidenciar suas dimensões qualitativas (eficácia e eficiência);

- as informações sobre desempenho devem transitar por canais que possibilitem ações no momento oportuno, em tempo hábil para implementação das correções que se façam necessárias;

- as informações devem ser direcionadas às pessoas que possuem autoridade e influência sobre as variáveis que requerem ações.

A avaliação de desempenho no contexto da gestão econômica viabiliza-se a partir da materialização dos modelos de decisão, mensuração e decisão. Esta materialização também permite que se desenvolva o processo de gestão da empresa.

Catelli et al. (1997:12) orientam que a avaliação de desempenho na gestão econômica baseia-se no modelo orçamentário e de apuração de variações, onde se destacam os seguintes elementos: orçamento original, orçamento corrigido, orçamento ajustado, orçamento realizado ao padrão, orçamento realizado efetivamente, variação de preço, variação de ajuste de plano, variação de volume e variação de eficiência.

A partir das considerações feitas, a configuração de um modelo de informação para avaliação de resultados e desempenhos na gestão econômica que possa ser aplicado as IFES seria conforme demonstra a Tabela 02:

O processo orçamentário desenvolve-se a partir 
Tabela 02: modelo de informação para avaliação de resultados e desempenhos na gestão econômica

Estrutura de
Resultado
(=) Margem de
Contribuição
Operacional
Operacional

das informações necessárias para apuração do resultado objetivado, sendo tais informações evidenciadas na coluna de orçamento original que deriva da quantificação dos planos da fase de planejamento operacional de médio e longo prazo, correspondendo às quantidades planejadas valoradas a preços planejados.

O orçamento corrigido deriva das correções das variações específicas de preço, correspondendo às mesmas quantidades especificadas no orçamento original. Tem o objetivo de segregar o efeito das variações de preços, representado o orçamento original com valores vigentes na época da realização dos eventos. $\mathrm{O}$ orçamento ajustado corresponde às quantidades planejadas para o curto prazo valorizadas pelos mesmos preços utilizados no orçamento corrigido.

A coluna do realizado refere-se às informações sobre os volumes das transações realizadas valoradas pelos mesmos preços do orçamento corrigido e ajustado considerando os insumos a partir do custo padrão (realizado ao padrão), e aos volumes das transações realizadas valoradas pelos preços correntes vigentes considerando os insumos a partir das quantidades reais efetivamente consumidas (efetivamente realizado).

A coluna das variações trata das informações so- bre a diferença calculada a partir do confronto entre os valores orçados originalmente e dos valores orçados corrigidos.

\section{CONCLUSÃO}

A avaliação das IFES torna-se um tema interessante à medida em que se possa perceber que os modelos tradicionais de avaliação a que são submetidas são inadequados, pois não evidenciam de uma maneira justa, consistente e coerente a real contribuição que estas trazem para a sociedade pela gestão econômica eficiente e eficaz dos recursos públicos.

Avaliar a verdadeira contribuição em termos de benefícios sociais diretos e indiretos gerados pelas IFES até o momento é uma tarefa impossível na prática. Não se conhece nenhum modelo que seja capaz de mensurar objetivamente e sem nenhum viés o impacto que, por exemplo, as 52 universidades federais exercem na sociedade brasileira ao desempenhar seu papel de promotoras do desenvolvimento econômico e social do país pela oferta de ensino público gratuito e de qualidade e do desenvolvimento de pesquisas científicas e tecnológicas responsáveis por demarcar a nossa posição no cenário mundial.

Se consideramos que ao cumprir seus objetivos 
econômicos as IFES estão cumprindo seus objetivos sociais, o modelo de avaliação que se deve aplicar na verificação do desempenho dessas instituições deve ser um modelo por resultado econômico. Neste contexto, o modelo conceitual para Gestão Econômica, como o delineado neste artigo, oferece as condições fundamentais para o desenvolvimento de uma gestão otimizadora dos resultados gerados pelas atividades de ensino, pesquisa e extensão das IFES, pois possibilita a mensuração desses resultados com base em conceitos econômicos, traduzindo de forma objetiva e consistente a eficácia no cumprimento da sua missão.

Pela sua configuração, o modelo permite também que se possa fazer uso de um modelo de informação integrado que permite: a) a captação de informações sobre os resultados previstos, os realizados favorecendo a identificação das variações ocorridas e informando os seus motivos; e b) a avaliação por parte dos gestores das suas ações, permitindo que possam implementar as medidas necessárias à otimização das ações gerenciais visando ao melhor resultado econômico da IFES.

Acreditamos que o resultado econômico seja a forma mais adequada para avaliar o desempenho de uma IFES, pois é abrangente e reflete objetivamente todos os indicadores de desempenho que possam ser identificados, tais como: operacional, de produtividade, social, educativo, cultural, qualitativo, quantitativo, temporal, tecnológico, funcional etc.

\section{REFERÊNCIAS BIBLIOGRÁFICAS}

ALMEIDA, Lauro Brito de - Estudo de um modelo conceitual de decisão, aplicado a eventos econômicos, sob a ótica da gestão econômica. Dissertação de Mestrado apresentada à FEA/USP - São Paulo, 1996 .

AMORIM, Antônio. Avaliação institucional da universidade. São Paulo: Cortez, 1992.

BACKER, Morton \& JACOBSEN, Lyle E. - Contabilidade de custos: um enfoque de administração de empresas - Rio de Janeiro, MacGraw-Hill do Brasil, 1978.

BELLONI, Isaura. A Universidade e o Compromisso da Avaliação Institucional na Reconstrução do Espaço Social in Avaliação - Revista da Rede de Avaliação Institucional da Educação, Campinas, Unicamp, n.ำ 2, Dez. 1996, p 5 - 14.

BEUREN, Ilse Maria - Modelo de mensuração do resultado dos eventos econômicos empresariais - Um enfoque de sistema de informação de gestão econômica - Tese de Doutorado apresentada à FEA/USP - São Paulo, 1994.

BERLINER, Callie \& BRIMSON \& JAMES A. Gerenciamento de custos em indústrias avançadas. São Paulo, T. A. Queiroz, 1992.

$\mathrm{BIO}$, Sérgio R. - Sistemas de informação: um enfoque gerencial - São Paulo: Atlas, 1985.

BRAGA, Nice. O processo decisório em organizações brasileiras. Revista de Administração Pública, Rio de Janeiro, v. 21, n. 3, p. 35-57, jul./set. 1987.

BENEDICTO, Gideon Carvalho - Contribuição ao estudo de uma sistema de contabilidade gerencial para uma gestão eficaz das instituições de ensino - Tese de Doutorado apresentada à FEA/USP - São Paulo, 1997.

CATELLI, Armando (Coordenador) - Controladoria: Uma abordagem da gestão econômica - GECON - São Paulo, Atlas, 1999.

- Sistema de contabilidade de custos estândar - São Paulo, Tese de Doutoramento, FEA/USP,1972.
, et al.- Sistema de gestão econômica - GECON: um instrumento para mensuração, otimização e avaliação de resultados e desempenhos - Conselho Regional de Contabilidade de São Paulo - Revista de Contabilidade do CRC-SP, ano II, n.ํ5, outubro de 1998.

CAVENAGHI, Vagner. - O modelo de gestão econômica aplicado à área de produção - uma contribuição da controladoria ao novo paradigma da produção - Dissertação de Mestrado apresentada à FEA/USP - São Paulo, 1996.

CRUZ, Rosany Ipaves. Uma contribuição à definição de um modelo conceitual de gestão econômica. Dissertação de Mestrado apresentada à FEA/USP, São Paulo, 1991.

DESORDI, Mara Regina Lemes - Avaliação institucional: o papel do gestor frente às interfaces da avaliação interna e externa. Associação Brasileira de Mantenedores de Ensino Superior Revistas Estudos,

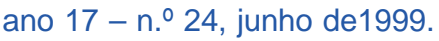

DURHAM, Eunice. SCHWARTZMAN, Simon. Avaliação do ensino superior. São Paulo, Edusp, 1992.

GUERREIRO, Reinaldo - Modelo conceitual de sistema de informação de gestão econômica: uma contribuição à teoria da comunicação da contabilidade - São Paulo, Tese de Doutoramento, FEA-USP., 1989.

Sistema de custeio direto padrão: estruturação e processamento integrado com os princípios de contabilidade geralmente aceitos - São Paulo, Dissertação de Mestrado, FEA-USP. 1984.

- A teoria das restrições e o sistema de gestão econômica: uma proposta de integração conceitual. Tese de Livre-Docência apresentada à FEA/USP, São Paulo, 1995.

HIRSCH, Maurice L. \& LOURDERBACK, Joseph G. - Cost accounting - accumulation, analysis and use - SouthWestern Publishing Co. - Cincinatti, Ohio, USA , 3. Edition, 1992. 
HORNGREN, Charles T. - Cost accounting: A managerial emphasis - New Jersey, Prentice-Hall, Inc. Englewood Cliffs, $3^{\mathrm{a}}$ ed., 1972.

IUDÍ́CIBUS, Sérgio de - Contabilidade gerencial - São Paulo, Atlas, 6aㅡ. Ed., 1998.

JOHNSON, H. Thomas \& KAPLAN, Robert S. - Relevance lost - the rise and fall of management accounting Boston, Harvard Business School Press, 1991.

LANG Theodore - Accountant's cost handbook - The Ronald Press Company - New York , USA, 1956.

LIMA, Iran Siqueira - Contribuição ao estudo da eficácia na aplicação do contrato de gestão nas empresas estatais - Tese de Doutorado apresentada à FEA/ USP, São Paulo, 1999.

OSTRENGA, Michael R. et all. Guia da Ernest \& Young para gestão total dos custos. Rio de Janeiro, Record,1993.

PARISI, Cláudio - Uma contribuição ao estudo de modelos de identificação e acumulação de resultados - São Paulo, Dissertação de Mestrado, FEAUSP, 1995.

PELEIAS, Ivam Ricardo - Avaliação de desempenho: um enfoque de gestão econômica - São Paulo, Dissertação de Mestrado, FEA-USP, 1992.

Contribuição à formulação de um sistema de padrões e análise de sua aderência ao processo de gestão, sob a ótica do modelo GECON - São Paulo, Tese de Doutoramento, FEA-USP, 1999.

PEREIRA, Carlos Alberto et al. Controladoria - Uma Abordagem da Gestão Econômica GECON - São Paulo, Atlas, 1999.

RISTOFF, Divo et al. Avaliação da Universidade Federal de Santa Catarina: uma proposta metodológica in Avaliação - Revista da Rede de Avaliação

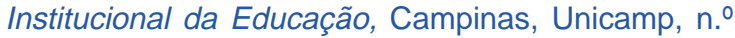
1, Jul. 1996, p 25 - 28.

SANTOS, Elci Pimenta Costa et al. O painel da escola: um instrumento de gestão à vista. Belo Horizonte, UFMG
- Escola de Engenharia, Fundação Christiano Ottoni, 1997.

SANTOS, Roberto Vatan dos - Modelos de decisão para Gestão de preços de venda - Dissertação de Mestrado apresentada à FEA/USP - São Paulo, 1995.

SLOMSKI, Valmor - Mensuração do resultado econômico em entidades pública - uma proposta - Dissertação de Mestrado apresentada à FEA/USP - São Paulo,1996.

- Teoria do agenciamento do estado: uma evidenciação da distribuição da renda econômica produzida pelas entidades públicas de administração direta - Tese de Doutorado apresentada à FEA/ USP - São Paulo,1999.

SCHWARTZMAN, Simon - Funções e avaliação do ensino superior. Documento de trabalho do Núcleo de Pesquisas Sobre Ensino Superior (NUPES). Brasília, 1989.

- A avaliação superior no Brasil: contexto e progressos. Texto preparado para o Seminário sobre Sistemas Nacionais de Avaliação, USP, 1991.

- A problemática da avaliação: excelência acadêmica e maturação institucional. CEDATE, Brasília, 1986. (não publicado).

TEJEDOR, Francisco J T; BLANCO, Laurentino S. La Evaluación Institucional en el Âmbito Universitário. in Avaliação Revista da Rede de Avaliação Institucional da Educação, Campinas, Unicamp, n.ำ 4, Jun. 1997, p 9 - 18.

VASCONCELOS, Marco Túlio de Castro. O processo de gestão de finanças sob a ótica da gestão econômica - Dissertação de Mestrado apresentada à FEA/USP. São Paulo, 1994.

. Modelo para avaliação de desempenho: uma aplicação à atividade de extensão universitária. Tese de Doutorado apresentada à FEA/USP. São Paulo, 1999. 